\title{
Cystic ameloblastoma in a 5-year-old boy
}

Wassermann, Veronika ; Huisman, Thierry A G M

DOI: https://doi.org/10.1007/s00247-007-0716-6

Posted at the Zurich Open Repository and Archive, University of Zurich ZORA URL: https://doi.org/10.5167/uzh-156493

Journal Article

Published Version

Originally published at:

Wassermann, Veronika; Huisman, Thierry A G M (2008). Cystic ameloblastoma in a 5-year-old boy. Pediatric Radiology, 38(4):482.

DOI: https://doi.org/10.1007/s00247-007-0716-6 


\title{
Cystic ameloblastoma in a 5-year-old boy
}

\author{
Veronika Wassermann • Thierry A. G. M. Huisman
}

Received: 9 November 2007 / Accepted: 26 November 2007 / Published online: 8 January 2008

(C) Springer-Verlag 2007

A 5-year-old boy presented with an indolent swelling of the left mandible without displacement or loosening of the teeth. A panoramic radiograph showed a large, well-defined, "bubbly", multiloculated, lucent expansile lesion within the left posterior mandibular body and angle (Fig. 1). A contrastenhanced CT scan showed a low-attenuation lesion with scalloping and partial resorption of the buccal and lingual mandibular cortex. The adjacent soft tissues were displaced; there was no extraosseous extension (Fig. 2). Tumor biopsy confirmed the presumed diagnosis of ameloblastoma. Resection of the left mandibular body/angle with immediate reconstruction was undertaken.

Ameloblastomas are benign epithelial neoplasms that develop from various sources of odontogenic epithelium $[1,2]$; they represent $10 \%$ of all odontogenic tumors. Most ameloblastomas occur in the ramus and posterior body of the mandible $(80 \%)$. They are usually seen in the third or fourth decade of life, but also occur in children. Their radiographic appearance varies. Differentiation from odontogenic keratocysts, odontogenic myxomas, aneurysmal bone cysts, and giant cell granulomas is limited $[1,2]$. CT and MRI are helpful in exactly delineating and determining the extension of the lesion, but imaging is not pathognomonic [2]. Tumor biopsy remains mandatory.

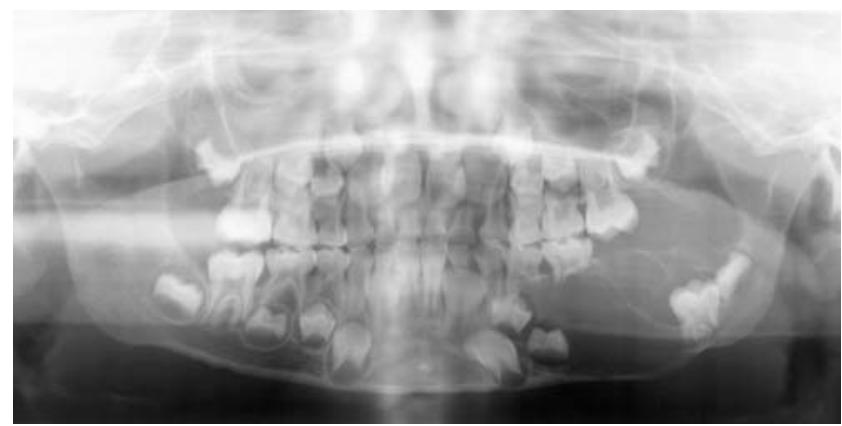

Fig. 1 Panoramic radiograph

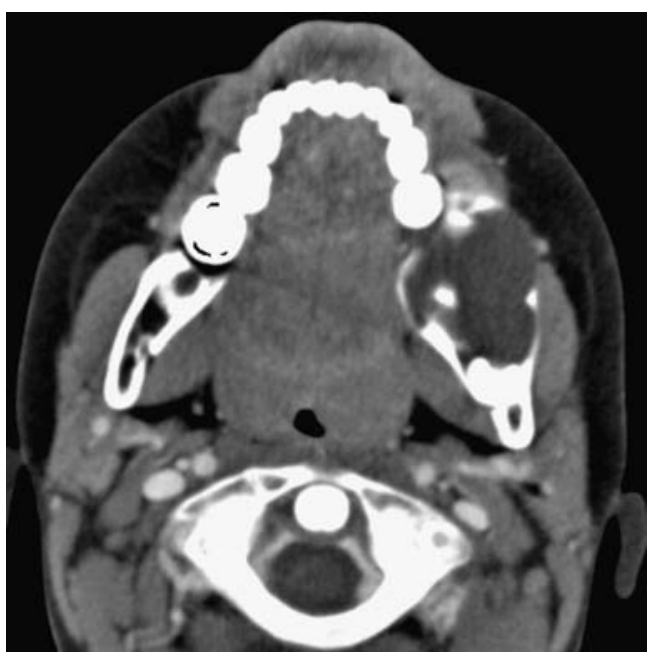

Fig. 2 Contrast-enhanced CT image

\section{References}

1. Cihangiroglu M, Akfirat M, Yildirim H (2002) CT and MRI findings of ameloblastoma in two cases. Neuroradiology 44:434437

2. Asaumi J, Hisatomi M, Yanagi Y et al (2005) Assessment of ameloblastomas using MRI and dynamic contrast-enhanced MRI. Eur J Radiol 56:25-30 